\title{
A ENFERMAGEM NA PREVENÇÃO DE INFECÇÕES NA CORRENTE SANGUÍNEA POR CATETER VENOSO CENTRAL
}

\section{ARTIGO ORIGINAL}

LIMA, Naara de Novaes Mendes Costa ${ }^{1}$

LIMA, Naara de Novaes Mendes Costa. A enfermagem na prevenção de infecções na Corrente Sanguínea por Cateter Venoso Central. Revista Científica Multidisciplinar Núcleo do Conhecimento. Ano 05, Ed. 04, Vol. 05, pp. 05-32. Abril de 2020. ISSN: 2448-0959, Link de acesso:

\section{https://www.nucleodoconhecimento.com.br/saude/cateter-venoso-central}

\section{RESUMO}

O cateter representa hoje um grande avanço tecnológico, pois trata-se de um aparelho vascular de admissão periférica de localidade centralizada, tendo um lúmen único ou duplo, composto de poliureano ou silicone, que auxilia no tratamento e melhora do paciente, impedindo assim múltiplas punções e um sofrimento desnecessário. Portanto, esta pesquisa visa apresentar como o enfermeiro deve atuar nos cuidados com o Cateter Venoso Central (CVC), prestando uma assistência integral e assegurando o paciente de possíveis danos. O presente estudo se justifica em razão do interesse sobre o tema, devido a vontade de aprimorar os conhecimentos acerca do dispositivo e primar pela segurança e recuperação do paciente. Para tanto, o método de pesquisa aproveitado foi a revisão de literatura. Concluiu-se que é necessário o uso de cuidados sistematizados, regras conferidas por evidências, certa segurança e qualidade ao trabalho desempenhado pela equipe da Unidades de Terapia Intensiva (UTI), levando assim a uma efetiva redução nas taxas de infecções.

\footnotetext{
1 Pós- Graduação em Enfermagem do Trabalho e Comissão de Controle de Infecção Hospitalar.
} 
Palavras-Chave: Cuidados, Cateter Venoso Central, enfermagem, infecção, prevenção.

\section{INTRODUÇÃO}

O cateter representa hoje um grande avanço tecnológico, já que pode ser definido como um dispositivo vascular de admissão periférica com localização centralizada, com lúmen único ou duplo, composto de poliureano ou silicone, que auxilia no tratamento e melhora do paciente, impedindo assim múltiplas punções e um sofrimento desnecessário.

Cateteres venosos são essenciais na assistência à saúde, particularmente na Unidades de Terapia Intensiva (UTI), ou seja, pacientes hospitalizados em estado crítico têm em seu tratamento com indicação de Cateter Venoso Central (CVC), pois esse desempenha um grande papel no tratamento desses indivíduos. Em UTIs, os riscos de infecções podem aumentar, pois há uma ampla variedade de microrganismos que muitas das vezes são multirresistentes, entrando em contato com pacientes debilitados imunologicamente agravando ainda mais o quadro inicial do paciente. Sendo assim, conhecer os cateteres e os locais onde serão implantados torna-se crucial para a diminuição dos eventos adversos possíveis.

Sabe-se que os locais mais utilizados para a inserção de cateter são a veia subclávia, femoral e jugular interna. Diante disto, o conhecimento das técnicas em relação à anatomia e à fisiologia do paciente auxiliam muito na atenuação dos agravos. Mediante a Lei no 7.498, que dispõe sobre o Exercício Profissional de Enfermagem, no seu parágrafo único e inciso I do Art. 11, tem-se que o enfermeiro é o responsável pelo controle e prevenção de Infecções Relacionadas à Assistência da Saúde (IRAS). Portanto, o profissional deve realizar cuidados com a manutenção e ter uma avaliação diária do local, com a finalidade de diminuir os riscos relacionados ao desenvolvimento de infecções.

Todavia, pode-se ressaltar que há fatores extrínsecos que podem influenciar no risco dessas infecções, como a falta de educação continuada dos profissionais de saúde, o 
descumprimento das técnicas assépticas e das normas que regem a proteção do paciente. Dessa forma, indaga-se como questão problema: quais os cuidados de enfermagem que o profissional deve ter com o CVC para que o paciente tenha um tratamento livre de danos?

Dessa maneira, o atual estudo tem como objetivo evidenciar como o enfermeiro deve atuar nos cuidados com o CVC, prestando uma assistência integral e assegurando o paciente de possíveis danos. Como objetivos específicos, busca-se apresentar conceito, histórico e características do CVC, exibindo a localização mais adequada para a inserção do CVC conforme as características do paciente; e exibir orientações e cuidados na manutenção do CVC.

O presente estudo se justifica em razão do interesse sobre o tema, que foi devido à vontade de aprimorar os conhecimentos pessoas acerca do dispositivo, primando pela segurança, assim como pela recuperação do paciente. $O$ tema se mostra relevante pela necessidade de descrever a implantação de um plano de cuidados de enfermagem, para que haja uma assistência de qualidade, e com isso, reduzir o risco de contaminação e remoção não eletiva do CVC.

A atuação na área despontou que há uma importância em elucidar que os cateteres de curta permanência são amplamente recomendados nos casos onde a terapia tenha duração pressagiada entre dez e quinze dias. Julga-se importante mostrar, tanto para profissionais da área quanto para os acadêmicos, que estes são dispositivos largamente usados em razão da gama de indicações e a facilidade de punção.

Diante disto, o tema aqui abordado mostra que, diante do extenso uso e as complicações pertinentes ao CVC, a enfermagem precisa proporcionar uma série de cuidados pertinentes ao dispositivo, desde a ocasião da introdução até a remoção do cateter. Sendo assim, um amplo aparato de dispositivos tecnológicos pertinentes ao cateter se encontra disponível no mercado, de maneira que a opção pela melhor prática para anticoncepção de complicações torna-se complicada. 


\section{INFECÇÃO HOSPITALAR}

\subsection{BREVES CONCEITOS}

A infecção, de um modo geral, alude-se ao desenvolvimento, à invasão e à multiplicação de um microrganismo no interior do organismo, e, por conseguinte, ocasionando doenças. Esta invasão dissemina no hospedeiro um conjunto de reações do sistema imunológico, com o objetivo de defender o sítio afetado e resultando, comumente, em inflamações (TAVAES, 2007).

De tal modo, pode-se notar que a expressão "infecção" e "inflamação", diversas vezes confundidas, possuem suas características. A inflamação pode acontecer não apenas quando existe a invasão por bactérias, vírus, protozoários ou fungos (TURRINI, 2000).

Neste contexto, a sinusite, por exemplo, trata-se de uma inflamação nos seios da face e, além disso, não se diferencia como uma infecção, pois não é ocasionada por um patógeno. Entretanto, a caxumba, por exemplo, trata-se de uma doença assinalada pela infecção de um vírus classificado como sendo do gênero Rubulavirus, da família Paramyxoviridae. Sua compleição procede na inflamação das glândulas salivares exibindo, no sítio, uma inchação peculiar (TAVAES, 2007).

Especificamente, a infecção hospitalar é conceituada por Nogueira e Couto (2000, p. 43) como sendo "a infecção obtida posteriormente a aceitação do paciente e que se desponta depois da internação ou a alta, quando puder ser conexa com a internação ou procedimentos hospitalares".

Frente a isto, a vigilância epidemiológica ativa trata-se de um dos pilares do controle das infecções hospitalares, já que admite a deliberação do perfil endêmico das instituições, a identificação de eventos inesperados (surtos) e o direcionamento das ações de anticoncepção e controle. A segurança do paciente é um fator que avalia o monitoramento das infecções hospitalares (TURRINI, 2000).

Essas infecções hospitalares constituem-se como um problema da saúde pública nacional, considerado como grave. São importantes causas de morbidade e 
mortalidade conexa com indivíduos submetidos a algum tipo de método clínicocirúrgico como meio de tratamento. Na Lei Federal no 8.080/1990, que trata acerca das condições para a promoção, proteção e recuperação da saúde, assim como a organização e funcionamento dos serviços adequados, o controle das infecções conexas com a assistência à saúde, está incluso no campo da epidemiologia (NOGUEIRA; COUTO, 2000).

Tido como sendo um conjunto de ações capazes de promover o conhecimento, o reconhecimento ou anticoncepção de qualquer alteração nos fatores determinantes da saúde pessoal ou coletiva, possui o objetivo de recomendar e adotar ações de controle e anticoncepção das doenças, bem como os seus agravamentos (OLIVEIRA, 2008).

Assim, observa-se que conhecer a ocorrência, bem como os determinantes das doenças e agravamentos à saúde, é de suma importância para instigar as ações para anticoncepção. Consequentemente, Turrini (2000, p. 50) explica que a infecção hospitalar "se trata da ocorrência em questão, uma doença que fazer parte da Classificação Estatística Internacional de Doenças e Problemas Relacionados à Saúde (CID-10)".

Do mesmo modo, Tavares $(2007$, p. 36) relata que a infecção hospitalar é caracterizada como "uma patologia ocasionada, em grande parte das vezes, por diversos microrganismos (bactérias, fungos, vírus) cuja progressão está conexa com diversos fatores, tais como idade e tabagismo". Com o objetivo de diagnosticar este tipo de afecção, "é preciso que haja o uso de métodos que permitam agrupar os diferentes fatores, admitindo assim reconhecer a interferência da multicausalidade da doença".

\subsection{ASPECTOS HISTÓRICOS}

O surgimento das infecções hospitalares pauta-se com o aparecimento dos primeiros hospitais. Mais precisamente, segundo Fernandes (2000, p. 23), "ambos datam do ano de 330 A.C., no Império Romano", com a construção do primeiro hospital urbano, 
"ainda que se tenha relatado a construção do primeiro hospital no ano de 394 A.C"., na cidade de Roma. Em seguida, vários outros foram formados, como, por exemplo, o Hotel-Dieu, localizado na França, o qual tinha aproximadamente 1.200 leitos, onde vários deles eram compartilhados com os demais doentes.

Os hospitais, antigamente, eram estabelecidos pertos das catedrais, e tinham assim um papel caritativo, de assistência aos carentes, inválidos, nômades e doentes. Estes ambientes de segregação e de exclusão, idênticos aos albergues ou asilos, eram tidos como fonte inesgotável de doença em razão das particularidades sanitárias e de assistência problemática, não se fazendo presentes, assim sendo, nem o médico e tampouco a atividade terapêutica (LACERDA, 2002).

Além do mais, não dispunham de qualquer meio de sistemática assistencial que impedisse as contaminações entre os indivíduos ali socorridos, beneficiando assim a propagação de doenças, notadamente as de aspecto infeccioso. Portanto, o hospital era muito além de um ambiente de cura e cuidado, era uma verdadeira fonte de doença e ambiente de morte (FERNANDES, 2000).

Desde a época da Roma Antiga, passando pela Idade Média, as mulheres quase sempre que ofereciam assistência nos hospitais, na figura de freiras e demais indivíduos sem que houvesse qualquer grau de remuneração e qualificação. De acordo com Rangel et al. (2013, p. 30), "para aquelas mulheres tidas como pecadoras, convinha como uma forma de indulto dos seus pecados e mérito de piedades".

De tal maneira, segundo Jarvis (2001, p. 40), "em razão de apresentarem um aspecto social, os hospitais não eram usados antigamente por famílias com maior poder financeiro". Essas famílias concretizavam a assistência e os cuidados aos seus doentes na própria residência.

Até a metade do Século XVIII, o ambiente hospital não era destinado para o doente se curar, mas sim um ambiente para assistência aos indivíduos mais desprovidos que estavam falecendo. $\mathrm{E}$ em paralelo às condições problemáticas pelas quais se acomodavam os hospitais até o fim do século XVIII, notou-se inúmeros casos de 
infecções hospitalares, portanto, os indivíduos doentes assistidos nos hospitais advinham a desenvolver demais doenças por causa da hospitalização (LACERDA, 2002).

Nesta conjuntura, conforme Frank; Gastmeier e Rüdent (2001, p. 67), "pode-se dizer que as infecções apareciam nos hospitais em decorrência das problemáticas condições onde os doentes eram colocados e atendidos naqueles lugares". A fragilidade dessas condições, por sua vez, promoveu o progresso do conhecimento acerca do hospital, bem como o seu objetivo, que, gradualmente, adveio a possuir um novo papel na assistência à saúde.

A alteração deste paradigma caritativo-assistencial aconteceu no fim do Século XVIII, uma vez que houve conscientização de que o hospital não apenas poderia como também precisaria ser um utensílio de terapêutica, não pela ação para com a doença ou com o doente, mas também pelos efeitos negativos que ele ocasionava, como as desordens econômicas e sociais (JARVIS, 2001).

Também, segundo Foster; Krause e Gastmeier (2000, p. 96), o surgimento do capitalismo "veio a apoiar o procedimento da reestruturação dos hospitais, com a finalidade de estimar o corpo como componente principal para as forças de trabalho imprescindíveis ao modelo capitalista", bem como diminuir as despesas das instituições hospitalares que conservavam inativos e necessitados, elevando assim a sua manutenção.

Segundo Rangel et al. (2013, p. 70), os hospitais começaram então a sua gradativa reestruturação, "partindo de um ambiente de caridade para um ambiente de cura, bem como de observação, de saberes e de disciplina, com a admissão dos médicos, aperfeiçoando as condições de atendimento", tornando-os instituições mais funcionais, aceitando pacientes apenas com recomendação médica para impedir a superlotação e, assim, colaborando para o ensino.

Principiaram então a aparecer as ações básicas elementares que atuam no controle de infecção, visando atender a nova finalidade do hospital. Conforme Rangel et al. 
(2013, p. 31), na conjuntura histórica das infecções hospitalares, "no ano de 1847, expressivo valor concebeu Ignaz Philipp Semmelweis (1818-1865), médico cirurgião húngaro, que na cidade de Viena, em meio ao século XIX", analisando as elevadas níveis de infecção puerperal nas mulheres que haviam sido tratadas pelos médicos que antes tinham concretizado necropsias, estabeleceu o costume de higienização das mãos com solução clorada.

Sendo assim, de acordo com Rangel et al. (2013, p. 32), "Ignaz Philipp Semmelweis, com esta simples ação, obteve a diminuição de taxas de infecção de 17,6\% para 1,2\% dentro de um período de nove meses". Inicialmente com a contribuição do estudo de Semmelweis, foi-se constituindo paulatinamente a relação que existia entre os pacientes internados que exibiam as infecções e as mortes. Diante disto, segundo Fernandes (2000, p. 25), na Inglaterra, no fim do Século XIX:

Florence Nightingale (1820-1910), uma enfermeira inglesa célebre por ser pioneira no tratamento de feridos de guerra, durante a Guerra da Crimeia, concebeu uma expressiva importância histórica com seu apoio na (re)organização dos hospitais e, logo, na implementação de ações para o controle das infecções hospitalares, como a preocupação direcionada para os cuidados de higienização, o isolamento dos enfermos, o atendimento pessoal, o uso controlado da dieta e a diminuição de leitos no próprio ambiente, estabelecendo ações de organização, sistematização do atendimento e treinamento dos profissionais de saúde, notadamente as práticas higiênico-sanitárias que constituiu e que contribuíram para a diminuição das taxas de mortalidade hospitalar daquele tempo.

Em se tratando do Brasil, Rangel et al. (2013, p. 72) lembram que as referências iniciais acerca do controle das infecções hospitalares apareceram apenas "em meados da década de 1950, com questionamentos sobre as ações ambientais, práticas concernentes aos procedimentos invasivos como os métodos assépticos, procedimentos de esterilização de material hospitalar", além do surgimento de microrganismos resistentes pela utilização indiscriminada de antibióticos. 
Os relatos iniciais no Brasil referentes a casos de infecção hospitalar, apareceram em meados da década de 1950, e, ainda que se empregasse a expressão "contaminação hospitalar", mencionavam como fatores causadores a esterilização do material hospitalar, a utilização irracional de antibióticos e o aparecimento de microrganismos resistentes (FERNANDES, 2000).

Depois do ano de 1968, surgiram então as Comissões de Controle de Infecção Hospitalar $(\mathrm{CClH})$ iniciais no Brasil, ligadas a instituições de ensino primeiramente. Depois, no ano de 1976, o Governo determinou que seria necessária a concepção de $\mathrm{CCIH} \mathrm{em} \mathrm{hospitais} \mathrm{próprios} \mathrm{da} \mathrm{previdência,} \mathrm{porém,} \mathrm{tal} \mathrm{ação} \mathrm{não} \mathrm{causou} \mathrm{impacto} \mathrm{em}$ razão da ausência de fiscalização (RANGEL et al., 2013).

$\mathrm{Na}$ década de 1980, teve-se um expressivo progresso no controle das infecções, acontecendo diversos eventos concernentes ao assunto, induzindo a concepção de diversos CCIH nos hospitais espalhados pelo país. No ano de 1983, o Ministério da Saúde, forçado então pelos fatos difundidos na mídia concernentes a casos de infecções em hospitais, formulou a Portaria MS № 196/1986, a qual sugeria aos hospitais do país a concepção de CCIH (FERNANDES, 2000).

Já na década de 1990, observou-se um crescente enfraquecimento no Programa de Controle de Infecção Hospitalar Brasileiro, apesar de ter ocorrido a publicação da Portaria MS no 930/1992. Diante disto, a política de descentralização das medidas de saúde, protegida pela Lei № 8.080/1990, gerou a fragmentação e disseminação das bases de apoio em controle de infecção hospitalar do Ministério da Saúde (JARVIS, 2001).

O resultado desta descentralização gerou a concepção de núcleos de profissionais em determinados Estados, como São Paulo e Minas Gerais, com a finalidade de conservar trocas de experiências, originando assim as diferentes relações dos profissionais no controle de infecções (FOSTER; KRAUSE e GASTMEIER, 2000).

Assim, praticamente uma década depois da promulgação da Lei Federal ํㅜ 9.431, o Ministério da Saúde publicou a Portaria no. 2.616/1998, em vigor até a atualidade, que 
conserva a existência, de forma obrigatória, de um $\mathrm{PClH}$ em todos os hospitais brasileiros, aborda a organização e competências da CCIH e do Programa de Controle de Infecção Hospitalar $(\mathrm{PClH})$, além de estabelecer as definições e os critérios diagnósticos referentes às infecções hospitalares, dando orientações acerca da vigilância epidemiológica e de indicadores das infecções hospitalares (RANGEL et al., 2013).

De fato, com supracitado, nota-se que, apesar da existência de legislações e normativas para a devida prática do controle sanitário, nota-se a interferência de diversos discursos difundidos nestas ações, sejam de ordem econômica, política, técnica ou jurídica, causando confrontos dos mais diversos, que acabam por intervir nas ações da regulação sanitária (FERNANDES, 2000).

Assim, percebe-se que tais discursos, mesmo que não tenham a competência de transcorrer domínios técnicos e científicos, compõem relações de forças apropriadas de eliminar o cumprimento do exercício institucional pleno de controle de infecções hospitalares no país (LACERDA, 2002).

\section{CATETER VENOSO CENTRAL (CVC)}

\subsection{CONCEITOS E CARACTERÍSTICAS}

Como já visto antes, o Cateter Venoso Central (CVC) é considerado um dispositivo vascular de entrada periférica com localização central, com lúmen único ou duplo. São compostos de poliuretano ou silicone, sendo os de silicone mais flexíveis e em sua grande parte inertes (gerando menos irritação nas paredes dos vasos e menor interação medicamentosa) (FREITAS, 2000).

Têm parâmetros tais como: calibre, comprimento, diâmetro interno, diâmetro externo e priming (volume interno), que estão mencionados em tabelas de conversão que precisam acompanhar o produto. De acordo com Forauer e Alonzo (2000, p. 227), esses dispositivos podem ser encontrados em duas maneiras de apresentação: "Kit completo: campos cirúrgicos, torniquetes, fita métrica, soluções antissépticas, agulha 
introdutória, tesoura ou guilhotina, seringas, pinça auxiliar para inserção, gases, adesivos transparentes e cateter; Minikit: fita métrica, agulha introdutória e cateter."

Em síntese, o cateter de silicone é confiável, macio, flexível, não-trombogênico e biocompatível, enquanto o de poliuretano possui bioestabilidade, trombogenicidade e resistência química; tem paredes mais finas, tendo, todavia, maior durabilidade (ROCHA et al., 2006).

O CVC possui comprimento de 20 a $65 \mathrm{~cm}$, com calibre variando de 14 a 24 gauge e 1 a 5 french, e tem um ou dois lumens, marcados em centímetros para facilitar a admissão. São compatíveis com várias soluções, apropriadas de continuar longos períodos, e podem ser usados por qualquer paciente, desde que conste de uma avaliação precedente do profissional médico ou enfermeiro habilitado para tal (WINKLE; WHIFFEN; LIU, 2008).

\subsection{HISTÓRICO}

O CVC foi inicialmente apresentado na literatura por volta no ano de 1929, como uma opção de acesso venoso central através de via periférica, quando um médico clínico alemão então chamado de Forsman se auto cateterizou por meio de uma sonda uretral a partir de uma veia da fossa cubital. Em razão da precariedade dos materiais naquele tempo, não foi desenvolvido o procedimento (FREITAS, 2000).

Em meio a década de 1970, desenvolveu-se o cateter de silicone, empregado elementarmente em Unidades de Terapia Intensiva Neonatal (UTIN), entretanto, foi inicialmente do ano de 1980 que se notou a ampliação de sua utilização, em razão da fácil e simples introdução frente ao leito por profissionais da enfermagem e pelo aparecimento de programas voltados para a capacitação profissional (VENDRAMIM; PEDREIRA; PETERLINE, 2007).

Apenas no final da década de 1990 que então essa nova tecnologia adveio a ser usada no Brasil, entretanto, em pequena escala em razão do elevado custo e à carência de recursos financeiros para a importação e compra dos cateteres. Esta 
tecnologia é habitualmente aplicada hoje em dia, proveniente de seus múltiplos benefícios para os pacientes, especialmente os recém-nascidos (SCHÜLLER; MACIEL; ICHICAWA, 2005).

Os cateteres intravenosos periféricos, pouco tempo antes, eram avaliados como sendo a melhor alternativa para acesso venoso, em razão das elevadas percentagens de mortalidade e morbidade provenientes do uso de dispositivos de acesso central. $\mathrm{Na}$ área da terapia infusional, o uso do CVC é crescente, demonstrando-se assim como uma alternativa cada vez mais adotada em cuidado e manutenção, notadamente para recém-nascidos de elevado grau de risco (JESUS; SECOLI, 2007).

\subsection{TIPOS}

\subsubsection{CATETER VENOSO CENTRAL DE CURTA PERMANÊNCIA}

Os cateteres centrais de curta permanência trata-se daqueles que chegam aos vasos centrais (subclávia, jugular, femoral) por meio de venopunção direta, e não são tunelizados. Estes dispositivos não têm qualquer mecanismo para anticoncepção de colonização extraluminal, beneficiando assim o ingresso da flora microbiana da pele na corrente sanguínea. Estes são comumente aplicados quando existe uma necessidade de acesso central por breves períodos, caracteristicamente entre dez e quinze dias, de onde procede sua designação (WINKLE; WHIFFEN; LIU, 2008).

\subsubsection{CATETER VENOSO CENTRAL DE LONGA PERMANÊNCIA - TOTALMENTE IMPLANTADO}

Os cateteres denominados totalmente implantados não exibem qualquer parte exteriorizada em seguida a sua acomodação. Na literatura internacional, faz-se menção a este cateter como "PORT". Ainda que adéquem baixa interferência estética e maior liberdade a quem os usam, os cateteres de extensa permanência possuem como ponto negativo o seu acesso, visto que ocorre por meio de punção com agulha - ponto acentuado de admissível desequilíbrio, que precisa ser antecipadamente avaliado pelo profissional de enfermagem (MACHADO, 2005). 
Silva e Nogueira (2004, p. 45) avaliam que esses cateteres "são compostos por tubos flexíveis radiopacos fabricados de silicone, poliuretano ou de teflon. Têm uma câmara de titânio em uma das extremidades". A parte central desta câmara trata-se de uma membrana de silicone denominada de septo, onde são feitas as punções para ingresso ao dispositivo. Segundo Toma (2004, p. 39), podem exibir também particularidades exclusivas conforme o seu fabricante, como por exemplo: "Modelos caracterizados, valvulados, não valvulados, reservatórios revestidos com silicone, inteiramente em titânio escovado, orifícios para fixação por meio de suturas, arredondados, ovalados, com maior ou menor campo de punção, entre outros.'

Os cateteres de longa permanência, podem ser usados em pessoas de todas as idades, abrangendo crianças, em razão do conforto que causa ao se impedir muitas punções de acesso, especialmente em tratamentos de maior duração. Exibem menor risco de complicações quando colacionados aos de curta permanência (WINKLE; WHIFFEN; LIU, 2008).

Contudo, a segurança da técnica não evita em sua totalidade a ocorrência de complicações, que ocasionam ampliação da morbimortalidade dos pacientes em condição clínica combalida pela patologia de base e dos custos hospitalares. A inserção do cateter pode possuir diversas localizações como veias calibrosas da região torácica, dos membros superiores ou, em último caso, membros inferiores (MACHADO, 2005).

Bem depois da indicação clínica de implante deste dispositivo, e antes que ela aconteça, é de suma importância notar se as condições sociais do paciente admitem que seja concretizado este procedimento. Entre os benefícios do cateter totalmente implantado, vale ressaltar que este tipo de dispositivo dispensa a concretização de curativos, com ressalva do momento pós-operatório (SILVA; NOGUEIRA, 2004).

Seu período de conservação é de até trinta dias, o que procede em um custo mais baixo para o paciente em relação a utilização de materiais. Outro fato a ser notado, é que não intervém nas atividades cotidianas do paciente, tampouco na autoestima, aceito que fica inserido no tecido subcutâneo (WINKLE; WHIFFEN; LIU, 2008). 


\subsubsection{CATETER VENOSO CENTRAL DE LONGA PERMANÊNCIA SEMI-IMPLANTADO}

O cateter semi-implantando tem esse nome pelo fato do mesmo ser implantado em veia central, advindo por um "túnel" feito no tecido subcutâneo, deixando uma parte externada, onde se realiza o acesso ao sistema venoso central para implantação da terapia intravenosa (TOMA, 2004).

Na sua porção tunelizada, o cateter exibe uma "manga" ou "bainha", igualmente denominada de cuff, de dacron, em material poroso e biocompatível, concebido para promover maior adesão de fibrina, ocluindo o túnel à entrada de patógenos e promovendo uma maior retenção do próprio no tecido subcutâneo (MACHADO, 2005).

Seus modelos, apresentações, comprimentos, assim como algum dispositivo adicional, tipo válvula bidirecional em sua ponta proximal ou distal e diferenciação das vias por códigos de cores, mostram variação conforme a empresa que produz. São compostos por material flexível e radiopaco, podendo ser de silicone, poliuretano ou de teflon. Exibem-se com uma, duas ou três vias, independentes entre si, de comprimentos e calibres variados (WINKLE; WHIFFEN; LIU, 2008).

Estes são recomendados para pacientes submetidos a transplante de medula óssea, em razão da facilidade de administrar infusão de grandes volumes, dado o seu maior tamanho. E igualmente para pacientes pediátricos e hematológicos, já que, ao dispensar a utilização de agulhas, se mostra traumático para crianças, além de atenuar o risco de sangramentos (SILVA; NOGUEIRA, 2004).

Este tipo de dispositivo se mostra contraindicado nos casos de pacientes que não ambicionam ou que não dispuserem de condições de regressar ao local em que o implante do cateter foi realizado com o objetivo de concretizar a conservação que não precisa extrapolar sete dias, impedindo a ocorrência de obstrução, ou na condição de baixa higiene, somando a potencialidade de infecção, aceito que existe uma parte do cateter exteriorizada, que precisa de cuidados higiênicos, além de curativos. É 
contraindicado igualmente nos casos de metástases cutâneas, em razão da ampla potencialidade de infecções (TOMA, 2004).

Em se tratando do local de implante, como primeira alternativa, escolhem-se as veias umeral e axilar, pois a proteção com curativo e enfaixamento desta área é facilitada, precavendo, portanto, a tração acidental e a exposição do cateter. Como segunda alternativa, são selecionadas as veias jugulares internas, quando os acessos antecedentes não são viáveis. Não são usadas as veias safena e femoral, por motivos evidentes de dificuldade para acesso e possível trombose venosa (SILVA; NOGUEIRA, 2004).

\subsubsection{CATETER VENOSO CENTRAL DE INSERÇÃO PERIFÉRICA}

O Cateter Venoso Central de Inserção Periférica (CVCIP) é um dispositivo vascular de inserção periférica que se localiza na região central, sendo largamente usado em pacientes com terapia intravenosa. Esse tipo de cateter pode ser implantado por enfermeiros, desde que habilitados, conforme a Resolução do Conselho Federal de Enfermagem- COFEN no 258/2001 (WINKLE; WHIFFEN; LIU, 2008).

Este tipo de cateter é produzido em silicone ou poliuretano, sendo radiopacos, de extensão total, tendo variação entre 10 e $75 \mathrm{~cm}$. Exibem como vantagens: menor custo; menores riscos pertinentes ao cateter; elimina o uso de sala cirúrgica, podendo ser implantado em qualquer localidade, até mesmo no leito de internação ou em residências; demanda somente um raio $\mathrm{x}$ simples para ratificação de sua localização depois de ser implantado (SILVA; NOGUEIRA, 2004).

O CVCIP é recomendado, primeiramente, para tratamento quimioterápico de até um ano de duração prognosticada. Sua recomendação se encontra conexa com a necessidade de acesso venoso central, bem como às boas condições venosas periféricas do paciente. Outras recomendações são para pacientes de suporte terapêutico, até mesmo em terapia em domicílio, tanto para a instalação, quanto para conservação (MACHADO, 2005). 
Contudo, por diversas vezes, isto não é admissível em razão da deficiência do acesso venoso periférico. Podem ser preconizados igualmente nos casos de pacientes com lesões torácicas, coagulopatias, com comprometimento imunológico, respiratório, ou também nas impossibilidades físicas, como por exemplo, na cifose (SILVA; NOGUEIRA, 2004).

\subsection{LOCAIS ADEQUADOS PARA DE INSERÇÃO DO CVC}

As veias de punção são a veia basílica, cefálica e cubital; sendo nos membros inferiores a poplítea, safena e femural. Para concretizar a prática de uma terapia intravenosa, o profissional de enfermagem precisa ter pleno domínio em anatomia e fisiologia da pele e vascular (MACHADO, 2005).

A pele que fica sobrejacente a veia escolhida precisa estar sem hematomas, integra, sem edemas e sem sinais de infecção ou alterações anatômicas. A preservação da rede venosa periférica colabora significativamente para o sucesso no procedimento juntamente com a capacidade e destreza na hora da inserção do cateter (WINKLE; WHIFFEN; LIU, 2008).

A opção pela veia precisa ser avaliada pelas suas características, sendo imprescindível notar se são palpáveis, calibrosas e com menos curvaturas. A pele sobrejacente à veia de opção precisa ser sem hematomas, integra, sem edemas e sem sinais de infecção ou alterações anatômicas. A inserção do CVC necessita levar em consideração essas características, com o objetivo de alcançar sucesso em sua introdução e conservação (FURTADO, 2008).

A veia basílica surge no lado medial do arco venoso dorsal, seu diâmetro mede 0,6 a $0,8 \mathrm{~mm}$ e o comprimento cerca de 24 centímetros. A veia jugular externa é a mais visível, com alto riscos de infecção local. Sendo assim, indica-se puncionar a jugular externa direita, pois a jugular externa esquerda pode elevar-se para jugular interna ao oposto de progredir para a veia cava (LOURENÇO; KAKEHASHI, 2003). 
O CVC é disposto em posição central no momento em que sua ponta estiver na porção final da veia cava superior ou porção inicial da veia cava inferior. Em membros superiores, a cabeça e pescoço, extensão entre o local de punção até a clavícula e terceiro espaço intercostal são medidos. Para a punção em membros inferiores, mede-se o comprimento entre a região da punção advindo pela região inguinal até a umbilical, concluindo na região do apêndice xifoide (SECOLI; KISHI; CARRARA, 2006).

\section{AÇÕES DO ENFERMEIRO NA PREVENÇÃO DE INFECÇÃO EM CORRENTE SANGUÍNEA POR USO DE CVC}

\subsection{INFECÇÃO EM CORRENTE SANGUÍNEA POR USO DE CATETER}

As infecções hospitalares se mostram crescentes quando relacionadas ao uso do CVC, e dentre suas causas, estão presentes o tipo de cateter utilizado, a duração, o número de lumens, o tipo de infusão, a técnica usada para inserção, e até mesmo, o sítio de inserção. Sendo assim, faz-se necessária uma digna atenção desde o processo de inserção até o momento de sua retirada, a fim de que não haja complicações e uma possível evolução catastrófica, ainda mais em pacientes tidos como graves (MESIANO; HAMANN, 2007).

A inserção do CVC é escolhida para pacientes que não possuam condições reais de acesso venoso, administração de drogas que necessitam de uma infusão contínua, necessidade de motorização hemodinâmica, administração de nutrição parenteral e soluções hipertônicas ou irritativas para as veias periféricas, como por exemplo, fármacos que são utilizados em uma quimioterapia neoplástica (SIQUEIRA et al., 2011).

No uso do CVC, as complicações ocorrem por problemas mecânicos tais como ruptura do cateter, obstrução, perfuração do vaso, extravasamento, trombose, problemas ligados a infecções, sepse relacionada ao cateter, hematoma, o mal posicionamento do mesmo, pneumotórax etc. (MARQUES, 2011). 
Todavia, há divisões para as infecções ligadas ao uso do CVC, a saber: óstio, infecção do túnel, da bolsa, bacteremia, sendo que, identificá-las é de extrema importância, pois apenas assim pode-se iniciar um tratamento terapêutico para cada caso específico (SIQUEIRA et al., 2011).

A caracterização da infecção de óstio é dada através da saída de secreção purulenta que se estende até o orifício por onde se exterioriza o cateter, e essa se mostra como a de menor gravidade e possui uma boa resposta aos cuidados locais com certo tratamento sem a necessidade da retirada do cateter. Já a infecção do túnel do cateter correspondente a hiperemia e ou saída de secreção que se estende por valores maiores que $2 \mathrm{~cm}$ do orifício do CVC, não dispõe de boa resposta a antibioticoterapia isolada, o que favorece a necessidade da retirada do cateter (MESIANO; HAMANN, 2007).

A bacteremia associada ao uso do cateter está diretamente ligada a presença de febre e ou calafrios em pacientes que utilizam o CVC na ausência de outro foco infeccioso. Neste contexto, o tratamento recomendado é a antibioticoterapia e a retirada do cateter. Neste dado caso, recomenda-se a colheita de hemoculturas periféricas, além da cultura do próprio cateter, com o uso da técnica semi-quantitativa de Maki (MARQUES, 2011).

Quando há indicação de diagnóstico de infecções ligadas a corrente sanguínea, a hemocultura é recomendada, a fim de haver um isolamento e identificação de microrganismos presentes no sangue do paciente que se supõe ter uma infecção, podendo esta ser bacteremia ou septicemia. Ao passo que se comprova a presença de microrganismos no sangue, a hemocultura se mostra como um exame de significativo valor, visto que este processo conota uma importante complicação no processo infeccioso (MESIANO; HAMANN, 2007).

A coleta de sangue voltada para a hemocultura se mostra usual em unidades hospitalares, ainda mais em UTIs, onde o seu resultado determinará os caminhos terapêuticos a serem adotados pelos profissionais da saúde, favorecendo assim a 
melhor recuperação do paciente, e também contribuindo para a amenização da morbidade e mortalidade hospitalar (SIQUEIRA et al., 2011).

Sabendo-se que não há um foco identificado, sendo assim, nota-se que é necessário que se colha duas amostras de hemoculturas de sangue periférico, com a retirada do cateter e o direcionamento da ponta do cateter para a cultura. Quando ambos são positivos, é necessário que seja feito uma comparação entre microrganismos crescentes em ambas, sendo considerado infecção relacionada ao cateter quando houver crescimento do mesmo microrganismo nas duas culturas, e sendo acompanhado de sintomas clínicos de infecção da corrente sanguínea e não havendo outro foco infeccioso aparente (MESIANO; HAMANN, 2007).

\subsection{ORIENTAÇÕES E CUIDADOS NA MANUTENÇÃO DO CVC}

No dia a dia, precisa-se avaliar constantemente o membro em que foi introduzido o CVC, notar a compleição de dor no tórax, edema, mandíbula ou ouvido, e mensurar a circunferência do membro. Assim, uma das orientações é utilizar o flush do cateter com solução salina sempre usando seringa maior que $10 \mathrm{cc}$ para impedir a oclusão intralúmen do cateter a qual tem possibilidade de acontecer por trombos sanguinolentos ou pelo desenvolvimento de fibrina, proveniente da compleição de sangue no cateter depois de um processo inapropriado de limpeza do cateter ou fluxo retrógrado (BAIOCCO; SILVA, 2010).

Para diminuir a incidência de sepse, o método asséptico e o treinamento dos profissionais que estão envolvidos na assistência são importantes. Demais fatores, tais como: a remoção do dispositivo posteriormente o fim da terapia, a minimização do tempo da terapia com nutrição parenteral, a utilização de filtros antibacterianos em meio a infusão, a afirmação de uma conexão constante para administrar o medicamento, a utilização de adaptadores que permitem o acesso sem a abertura do cateter e a região de inserção ocluído a partir da utilização de um curativo estéril, são ações que precisam ser praticadas para diminuir a incidência da sepse (FRANCESCHI; CUNHA, 2010). 
Recomenda-se o CVC para recém-nascidos prematuros extremos, com recomendação de nutrição parenteral por um período prolongado, postos a situações cirúrgicas e com malformações e síndrome, estando igualmente preconizado em terapias hiperosmolares e em soluções com um pH considerado não fisiológico (SILVA; NOGUEIRA, 2004).

No entanto, na UTI neonatal, a introdução do CVC é avaliada como sendo um procedimento de elevada complexidade, assim, o enfermeiro e o médico neonatologista são os profissionais responsáveis pelo procedimento (FRANCESCHI; CUNHA, 2010).

Além da inserção, compete ao enfermeiro a conservação diária do cateter que envolve a concretização de curativos com o objetivo de criação de um ambiente seguro, protegendo, de tal modo, a área em que está alocado o cateter e, assim, prevenir um presumível deslocamento. A inserção do CVC demanda técnica de barreira máxima, a qual se manifesta na utilização de máscara, gorro, capote e campos estéreis sob a região de punção escolhida e antissepsia (GOMELLA et al., 2006).

Em razão da complexidade do procedimentos, indica-se ações prévias para a introdução do CVC, como a solicitação do setor de radiologia com a compleição de um técnico para fazer radiografia de tórax ao introduzir o cateter; promover a assepsia das mãos e a avaliação das condições do paciente; providenciar e checar o material imprescindível para implemento do procedimento; atuar promovendo 0 posicionamento do paciente em decúbito dorsal, conservando o membro, de preferência o superior direito, em ângulo de $90^{\circ}$ com referência ao tórax; medir com fita métrica o perímetro braquial e o distanciamento entre o ponto de punção e a articulação escapuloumeral e, a partir desse ponto, até a fúrcula esternal e, logo, até o terceiro espaço intercostal (SILVA; NOGUEIRA, 2004).

A introdução do CVC deve obedecer um roteiro abrangendo as seguintes ações e cuidados: posicionamento do paciente; identificação da veia adequada; paramentação; antissepsia; averiguação da medida do comprimento do cateter; teste de permeabilidade do cateter; abertura total do material e colocação de um campo 
estéril sob a região de punção selecionado; lubrificação do cateter com solução salina; preparação do comprimento do cateter; aplicação de torniquete e preparo do conjunto introdutor; remoção da agulha da bainha introdutora; inclusão do cateter periférico; execução de venopunção; retirada da bainha protetora; introdução total do cateter periférico; remoção do campo fenestrado; fixação do cateter; limpeza da região de inserção; fixação do disco oval; confirmação radiológica da posição da ponta do cateter fechamento do sistema; (BITTENCOURT; LAMBLET; SILVA apud KNOBEL, 2006).

No que se refere à manutenção do CVC, estimada como um dos maiores desafios para os enfermeiros por causa do calibre estreito e da probabilidade de oclusão e infecção, alude-se ao curativo diário feito na região da inserção do cateter, assim como identificar e acompanhar os sinais precoce de infecção, infiltração e demais intercorrências pertinentes à infusão de soluções prescritas e à permeabilidade (MACHADO, 2005).

A mudança do curativo solicita a remoção manual do filme transparente semipermeável (em razão de proporcionar melhor visualização da região de inserção), com utilização de luvas esterilizadas, para remover a fita adesiva hipoalergênica, averiguação da localização do cateter para que haja a confirmação de ausência de deslocamento; limpar o região com gaze esterilizada encharcada numa solução de clorexidina a 0,5\%, posicionar, depois disso, o cateter e utilizar uma fita adesiva em cima do disco oval objetivando mantê-lo no local; por de novo fitas adesivas e o filme transparente acima da região de inserção (BITTENCOURT; LAMBLET; SILVA apud KNOBEL, 2006).

Há também recomendação de que o grupo de enfermagem necessita fazer uma assepsia das conexões sempre que o sistema for manuseado, em razão da probabilidade do acontecimento de complicações locais e sistêmicas. O enfermeiro necessita ser capaz a ter reconhecimento dos riscos e das complicações provenientes do dispositivo, assim como a tratá-las (JESUS; SECOLI, 2007). 
Para tanto, precisa procurar por informações atuais acerca do assunto. Além do que, precisa-se destacar a necessidade de promover treinamento para toda a equipe de enfermagem com o objetivo de ensinar o manejo do dispositivo, por causa da prática da terapia intravenosa ser realizada, no Brasil, por todos os profissionais (MACHADO, 2005).

E por fim, os profissionais de enfermagem precisam notar sinais de hiperemia, sangramento, tração do cateter, assim como, o seu funcionamento, detectando, dessa forma, perfurações, obstruções e demais intercorrências que possam afetar a viabilidade funcional dos enfermeiros (FURTADO, 2008).

\subsection{AÇÕES DO ENFERMEIRO NA PREVENÇÃO DE INFECÇÃO EM CORRENTE SANGUÍNEA POR USO DE CVC}

O CVC atua desempenhando um papel importante no tratamento de paciente hospitalizados, especialmente os que apresentam um estado crítico. A UTI, vale-se de medidas como dispositivos invasivos e diagnósticos os quais podem promover o desencadeamento de complicações como as IRAS (NEVES JUNIOR et al., 2010).

Em uma UTI, tem-se a percepção de que as infeções hospitalares se ampliam devido à uma gama de microrganismos multirresistentes, onde há a implicação de antimicrobianos de amplo espectro. Tem por característica procedimentos invasivos que possibilitam o diagnóstico ou cura do paciente, tornando o controle de infecções complicado. A infecção por parte da corrente sanguínea central se mostra como a principal complicação do CVC (FURTADO, 2008).

Ocorrem anualmente nos Estados Unidos uma estimativa de 340 mil a 470 mil IRAS, o que gera uma razão de 17 a 36\% de mortalidade. Foi realizado, no Brasil, um estudo com 33 pacientes internados em uma UTI com o uso de $50 \mathrm{CVCs}$. Ao passo que 18 pacientes foram diagnosticados com infecção na corrente sanguínea relacionada ao cateter, em um cenário clínico, 20\% destes pacientes foram a óbito (ANDRADE; BORGES; LIMA, 2011). 
Houve um percentual de 1,52/1000 cateteres que levaram a infecção sanguínea primária por dia, e a taxa do uso de cateteres foi de 0,80 . Sendo assim, fica claro que é necessário que os profissionais dessa área possuam conhecimento das IRAS e não autorizem taxas superiores a 0,51/1000 CVC por dia (FURTADO, 2008).

Sendo assim, é notada a preocupação com os riscos expostos ao paciente de infecção, como o constante quadro de infecção na corrente sanguínea associadas ao cateter venoso central, a necessária melhoria no cuidado na inserção e na manutenção dos cateteres venosos profundos, assim como, a adoção de medidas baseadas em evidências para que se possa embasar o cuidado do grupo de saúde (NEVES JUNIOR et al., 2010).

É necessário também o uso de cuidados sistematizados, regras conferidas por evidências, certa segurança e qualidade ao trabalho desempenhado pela equipe da UTI, levando assim a uma efetiva redução nas taxas de IRAS. Desta maneira, de acordo com Mendonça et al. (2011, p. 40), as medidas de enfermagem oferecidas para a prevenção de infecções hospitalares em corrente sanguínea são as seguintes:

Admissão do Cateter:

- Usar um checklist de inserção de cateter central para que se possa garantir as ações preventivas de Infecção Primária da Corrente Sanguínea (IPCS) no tempo da admissão do cateter;

- Usar kits de admissão de cateter que possuam todos os insumos imprescindíveis para admissão do cateter central;

- Higienizar as mãos antes e em seguida a admissão, assim como para demais manipulações do cateter;

- Aproveitar barreira máxima estéril na ocasião de admissão do cateter central; 
- Manter um campo estéril expandido, de maneira a acobertar inteiramente o corpo do paciente;

- Os profissionais que atuam na admissão do cateter necessitam utilizar gorro, máscara, avental estéril de manga comprida, luvas estéreis e óculos protetores;

- Preparar a pele do paciente com uma solução alcoólica de gliconato de clorexidina $>0,5 \%$;

- Esperar a secagem natural do antisséptico anteriormente ao procedimento de punção;

- Não fazer o procedimento de punção em veia femoral de rotina, já que a admissão nesse sítio se encontra conexa a elevados riscos de infecção.

Conservação do Cateter:

- O manuseamento precisa ser antecedido de higienização das mãos;

- Deve-se utilizar gazes e fitas adesivas estéreis ou cobertura transparente semipermeável estéril que possa cobrir o espaço de admissão;

- Precisa-se fazer a troca da cobertura com gaze e fita adesiva estéril a cada 48 horas ou a cada sete dias caso se use uma cobertura estéril transparente;

- Qualquer tipo de cobertura necessita ser substituída de imediato, independente do prazo, se estiver suja, solta ou úmida;

- Fazer a desinfecção das conexões, conectores valvulados e ports de adição de medicamentos por meio de solução antisséptica de álcool, 
com movimentos aplicados de maneira a causar um atrito mecânico, de cinco a quinze segundos;

- Deve-se avaliar, minimamente, uma vez por dia, o local de admissão dos cateteres centrais, através de uma inspeção visual e palpação sobre o curativo incólume.

Remoção do Cateter:

- Deve-se retirar os cateteres dispensáveis;

- Os cateteres inclusos em caso de emergência ou sem o emprego de barreira máxima necessitam ser movidos para outro local assim que admissível, não excedendo 48 horas;

- Deve-se reavaliar todos os dias a necessidade de conservação do cateter, com imediata retirada daqueles que são dispensáveis;

- Não se deve fazer a troca pré-programada dos cateteres centrais, portanto, não os substituir de forma exclusiva em razão de tempo de sua conservação.

É de suma importância determinar prioridades nas investidas de prevenção e controle das IRAS. É necessário priorizar a padronização e o estabelecimento de políticas que sejam voltadas para a implantação e a manutenção de procedimentos invasivos (ANDRADE et al., 2010).

Se mostra fundamental também que haja um acompanhamento de boas práticas referentes à execução de procedimentos, amostra de indicadores de resultado e uma avaliação criteriosa da estrutura. É necessário apontar ainda que, quanto melhor as condições estruturais, é mais provável que se adquira não só um processo adequado, mas também resultados mais favoráveis (FURTADO, 2008).

Um dos principais objetivos da vigilância das IRAS é prover informativos que possam ser utilizados pela instituição para a promoção de contínua melhoria, formalizando 
estratégias preventivas e o controle de infecções. Há inúmeras publicações que apontam que a vigilância epidemiológica, assim como a implementação de medidas preventivas, controle dirigidos e a divulgação das informações podem levar a redução significativa das infecções (ANDRADE; BORGES; LIMA, 2011).

O intuito é que se conheçam dados endêmicos de IRAS, a identificação de possíveis surtos epidemiológicos, bem como a proposição e desenvolvimento de diretrizes de controle e prevenção de infecção. Andrade; Borges e Lima (2011, p. 43) afirmam que "é extremamente recomendado que se use a vigilância de Pneumonia Associada à Ventilação (PAV) em UTI, assim como o cálculo de suas taxas", promovendo o acesso desses índices a equipe de saúde e, acima de tudo, que se desenvolva a associação destas taxas com as medidas de prevenção padronizada.

Tal indicador tem um potencial para ser um aliado na avaliação da qualidade da assistência. Portanto, é necessário que a vigilância seja efetuada por equipe treinada com conceitos e epidemiologia e critérios definidos de pneumonia. Segundo Andrade et al. (2010, p. 64), "é necessário que os treinamentos sejam desenvolvidos em conjunto com o Serviço de Controle de Infecção Hospitalar $(\mathrm{SClH})$, a área de treinamento - educação continuada - e a unidade de internação".

A fim de atender as demandas de prevenção e controle das IRAS, os profissionais que atuam neste controle necessitam desenvolver estratégias inovadoras educacionais embasadas em práticas e em evidências, e que tenham adaptabilidade as necessidades de aprendizagem de instituições, bem como os seus públicos (FURTADO, 2008).

Neves Junior et al. (2010, p. 59) traz que as taxas de PAV recebem impacto direto do treinamento da equipe multiprofissional que assiste aos pacientes em ventilação mecânica. Neste contexto, as diretrizes devem se mostrar multimodais - metodologias variadas - "com treinamento de aula presencial, e-learning, aula prática com presença de simulações, discussão da prática à beira do leito, feedback de indicadores e discussão de medidas preventivas etc.". 
Portanto, é necessário que haja uma rotina de medidas multidisciplinares, assim como uma equipe capacitada, inserida diretamente na assistência aos pacientes internados na UTI, tendo em vista, também, a participação de médicos e enfermeiros da CCIH. Tais visitas à beira do leito possibilitam o gerenciamento de medidas de prevenção, além de uma aproximação com quadros e não conformidades dos processos assistencialistas, facilitando assim a relação entre profissionais (ANDRADE; BORGES; LIMA, 2011).

\section{METODOLOGIA}

O método aplicado para a realização do atual estudo foi o de revisão de literatura. Essa revisão de literatura foi realizada a partir da busca de artigos científicos publicados. O material foi obtido em sites de busca e nas bibliotecas virtuais como, por exemplo, Google Acadêmico e Scientific Electronic Library Online (SciELO).

Para os critérios de seleção, foram utilizados artigos publicados entre os anos de 2000 e 2019. Depois dessa fase, ocorreu uma triagem, sendo selecionado estudos que abordavam o assunto da pesquisa. O presente estudo é do tipo exploratório-descritivo, considerado como qualitativo.

A abordagem usada foi a qualitativa, em que houve a coleta de informações, as quais foram expostas e analisadas. Além disso, a observação de documentos, com a preocupação de colher e atentar para uma maior quantidade de elementos também foram realizadas. Assim, objetivando um maior e mais profundo entendimento do problema trabalhado.

\section{CONSIDERAÇÕES FINAIS}

O atual estudo elucidou com objetivo apresentar como o enfermeiro deve atuar nos cuidados com o CVC, prestando uma assistência integral e assegurando o paciente de possíveis danos. Desta maneira, concluiu-se que é necessário o uso de cuidados sistematizados, regras conferidas por evidências, certa segurança e qualidade ao 
trabalho desempenhado pela equipe da UTI, levando assim a uma efetiva redução nas taxas de IRAS.

Concluiu-se também que os cuidados diferenciados como os curativos e cateteres banhado com clorexidina ou antibióticos, bem como os sistemas de infusão fechados, previnem a infecção em corrente sanguínea. Constatou-se com o presente estudo que as ações de enfermagem se aludem inteiramente em cuidados que propendem diminuir a um mínimo admissível o risco dos pacientes submetidos ao uso de CVC de adquirirem uma infecção hospitalar.

Observou-se que tais ações, ainda que simples, demandam da equipe de enfermagem a adoção de práticas com a finalidade de impedir que os microrganismos pertinentes ao manejo do cateter, ou da própria microbiota do paciente, tornem o cateter deteriorado em razão da infecção na corrente sanguínea, assim como cessar ou adiar o tratamento, ou até mesmo a levar à sepse e ao falecimento.

Observou-se também que os conceitos de periodicidade devem ser reforçados através da higienização das mãos, devendo fazer parte de todas as campanhas educativas. A preparação alcoólica para tal processo necessita ser estimulada nas áreas de serviço voltado para a saúde, se fazendo ainda mais necessário no quadro de assistência/tratamento.

Assim sendo, para que se realize a higienização, notou-se que é preciso que se use produto alcoólico ou água e sabonete líquido, se houver a percepção de que as mãos estão visivelmente sujas. E para que tal processo se mostre eficaz, é necessário que se valha de técnica e que se atente a duração do processo, onde antes de se iniciar o processo, se mostra de suma importância a retirada de adornos - anéis, pulseiras, relógios - visto que possam dificultar a eliminação/remoção de microrganismos ou acumulá-los nas mãos.

Ademais, evidencia-se que o desenvolvimento do atual estudos foi de grande importância pessoal, uma vez que ressaltou os serviços relacionados à saúde, atualmente, devem estar adequados à RDC/ANVISA no 42/2010, onde se é 
determinado o uso de preparação alcoólica, com o objetivo de promover fricção antisséptica das mãos nos áreas de assistência e tratamento; este precisa estar localizado numa região visível e ser de fácil acesso. Por esta medida, tem-se o objetivo de que não haja necessidade de que os profissionais de saúde necessitem se evadir do local de assistência e tratamento que passem pelo processo de higienização.

Por fim, diante do exposto aqui, destaca-se que o profissional de enfermagem, junto com os outros profissionais do campo da saúde, possui uma expressiva importância no planejamento, realização e avaliação da programação das ações educacionais presentes na atuação da equipe de enfermagem, sendo imperativo que haja entendimento destas ações como instrumentos que possam ser utilizados na promoção da saúde.

Como sugestão para pesquisas futuras, sugere-se estudos que procuram averiguar se o conhecimento produzido em artigos científicos até os dias de hoje acerca das intercorrências de enfermagem é suficiente e capaz de prover apoio e orientações apropriadas para atenuar tais incertezas e os prováveis efeitos colaterais de todo o processo.

\section{REFERÊNCIAS}

ANDRADE, A. M; BORGES, K. S; LIMA, H. O. A avaliação das coberturas para sítio de inserção do cateter venoso central no TMO: análise de custos. Ver Min Enferm; 15(2), 2011.

BAIOCCO, G. G; SILVA, J. L. B. da. The Use of the Peripherally Inserted Central Catheter (Picc) in the Hospital Environment. Rev. Latino-Am. Enfermagem [online], vol. 18, no 06, 2010. Disponível em: http://dx.doi.org/10.1590/S010411692010000600013. Acessado em 12 de setembro de 2019.

BITTENCOURT, A; LAMBLET, L. C. R; SILVA, G. M. L. Cateter venoso central de inserção periférica. In: KNOBEL, E. Terapia intensiva enfermagem. São Paulo: Atheneu, 2006. 
BOGDAN, R. C; BIKLEN, S. K. Investigação qualitativa em educação: uma introdução à teoria dos métodos. Porto: Porto Editora, 1994. In: LIMA, P. G. Tendências paradigmáticas na pesquisa educacional. Campinas, SP: (s.n), 2001.

CERVO, A. L; BERVIAN, P. A. Metodologia Científica. 5ª ed. São Paulo: Pearson Pratice Hall, 2004.

FERNANDES, A. T. Infecção hospitalar e suas interfaces com a área de saúde. São Paulo: Atheneu, 2000.

FORAUER, A. R; ALONZO, M. Change in Peripherally Inserted Central Catheters Tip Position with Abduction and adduction of the Upper extremity. J Vasc Inter Radiol; 11(10), 2000.

FOSTER, H. D; KRAUSE, G; GASTMEIER, P. Can quality circles improve hospitalacquired infection control? J Hosp Infect; 45, 2000.

FRANCESCHI, A. T; CUNHA, M. L. C. da. Adverse Events Related to the Use of Central Venous Catheters in Hospitalized Newborns. Rev. Latino-Am. Enfermagem [online], vol. 18, oㅜ 02, 2010. Disponível em: http://dx.doi.org/10.1590/S0104-11692010000200009. Acessado em 12 de setembro de 2019.

FRANK, U; GASTMEIER, P; RÜDENT, $H$. The organization of infection control in Germany. J Hosp Infect; 49, 2001.

FREITAS, L. C. M. Apostila 1: Conceitos teóricos Básicos Para Instalação de CCIP. Rio de Janeiro, CEI, 2000.

FURTADO, A. M. O. Análise da incidência de infecção dos cateteres venosos centrais em terapia intensiva. Monografia de Residência de Enfermagem. Escola de Enfermagem da Universidade do Estado do Rio de Janeiro, 2008.

GIL, A. C. Como elaborar projetos de pesquisa. São Paulo: Atlas, 2007. 
GIL, A. C. Como elaborar projetos de pesquisa. 4ª ed. São Paulo: Atlas, 2010.

GOMELLA, T. L et al. Neonatologia: manejo, procedimentos, problemas no plantão, doenças e farmacologia neonatal. Porto Alegre: Artmed, 2006.

JARVIS, W. R. Infection control and changing health-care delivery systems. Emerg Infect Dis; 7, 2001.

JESUS, C. V; SECOLI, S. R. Complicações acerca do cateter venoso central de inserção periférica (PICC). Ciência Cuidado Saúde; 6 (2), 2007.

LACERDA, R. A. Brazilian scientific production on nosocomial infection and nursing contribution: past, present and perspectives. Rev Lat Am Enferm; 10(1), 2002.

LIMA, T. C. S; MIOTO, R. C. T. Procedimentos metodológicos na construção do conhecimento científico: a pesquisa bibliográfica. Rev. Katál. Florianópolis, v. 10, 2007.

LOURENÇO, A. S; KAKEHASHI, T. Y. Assistência de enfermagem pré e pós inserção do cateter venoso central em pacientes neonatos. Nursing; 63 (6), 2003.

MACHADO, A. F. Estudo prospectivo, randomizado e controlado sobre o tempo de permanência de cateteres venosos periféricos em crianças, segundo três tipos de curativos. Rev Latino-Americana Enfermagem, Ribeirão Preto, v. 13, no 03, 2005.

MARQUES, B. P. Perfil bacteriano de cultura de ponta de cateter venoso central. Rev. Pan/Amaz Saúde; 2(1), 2011.

MENDONÇA, K. M; NEVES, H. C. C; BARBOSA, D. F. S; SOUZA, A. C. S; TIPPLE, A. F. V; PRADO, M. A. Atuação da enfermagem na prevenção e controle de infecção de corrente sanguínea relacionada a cateter. Rev Enferm UERJ; 19(2), 2011. 
MESIANO, A. E. R. B; HAMANN, E. M. Infecções da corrente sanguínea em pacientes em uso de cateter venoso central em unidades de terapia intensiva. Rev Latino-Am Enfermagem: v. 15, no 03, 2007.

NEVES JUNIOR, M. A; MELO, R. C; GOES JUNIOR, A. M. O; PROTTA, T. R; ALMEIDA, C. C; FERNANDES, A. R. Infecções em cateteres venosos centrais de longa permanência: revisão de literatura. J Vasc Bras; 9(1), 2010.

NOGUEIRA, J. M; COUTO, R. C. História do controle de infecção e a situação Brasileira. Healht Latin America, 2000.

OLIVEIRA, R. M. S. Controle de Infecção Hospitalar: Histórico e Papel do Estado. Rev. Eletr. Enferm; 10(3), 2008.

RANGEL, C. T; SARAIVA, E. M; SILVA, J. B; SILVA, E. M. M; SOUZA, M. L; OLIVEIRA, C. P. Caracterização das infecções relacionadas à assistência à saúde em uma unidade de terapia intensiva neonatal. Rev. enferm. UERJ, Rio de Janeiro, 2013.

ROCHA, K. S. G; BRAGA, E. S; BARRETOS, F. R. D; SÁ, M. S. Cateter epicutâneo no cotidiano da enfermagem a criança em pré-operatório de cirurgia cardíaca: Limites e desafios na instalação precoce. Rev. Esc Enferm Ana Nery. 2006.

SCHÜLLER, D. M; MACIEL, M. R; ICHICAWA, H. Cateter venoso central de inserção periférica em paciente com atendimento ambulatorial: estudo de caso. Nursing; 80(8), 2005

SECOLI, S. R; KISHI, H. M; CARRARA, D. Inserção e manutenção do PICC: Aspectos da prática clínica em saúde oncológica. Rev Prática Hospitalar; 8(47), 2006.

SILVA, G. R. G; NOGUEIRA, M. F. H. Terapia intravenosa em recém-nascidos. Rio de Janeiro: Cultura Médica, 2004. 
SIQUEIRA, G. L. G; HUEB, W; CONTREIRA, R; NOGUERON, M. A; CANCIO, D. M; CAFFARO, R. A. Infecção de corrente sanguínea relacionada a cateter venoso central (ICSRC) em enfermarias: estudo prospectivo comparativo entre veia subclávia e veia jugular interna. J. Vasc. Bras., Porto Alegre: v. 10, № 03, 2011.

TAVARES. W. M. Rotinas Diagnósticas e Tratamento Das Doenças infecciosas e parasitarias. 2aㅡ edição, São Paulo, Atheneu, 2007.

TOMA, E. Avaliação do uso do PICC em recém-nascidos. Tese de Doutorado. Faculdade de Enfermagem. Universidade de São Paulo, 2004.

TURRINI, R. N. Percepção das enfermeiras sobre fatores de risco para a infecção hospitalar. Ver. Ex. Enf. USP., v. 34, no 02, 2000.

VENDRAMIM, P; PEDREIRA, M. L. G; PETERLINE, M. A. S. Cateteres centrais de inserção periférica em crianças de hospital do município de São Paulo. Revista Gaúcha Enferm; 28(3), 2007.

WINKLE, P. V; WHIFFEN, T; LIU, I. A. Experience using peripherally inserted central venous catheters for outpatient parenteral antibiotic therapy in children at a community hospital. Pediatr Infect Disease J; 27(12), 2008.

Enviado: Fevereiro, 2020.

Aprovado: Abril, 2020. 